\title{
Families, Resources, and Suicide: Combined Effects on Mortality*
}

Justin T. Denney Rice University

Running head: Families, Resources, and Suicide

* Department of Sociology, MS-28, 6100 Main Street, Houston, TX 77005-1892 (jtdenney@rice.edu).

Acknowledgement: I am indebted to Fred Pampel and Rick Rogers for their insights throughout the development of this manuscript and I thank Kristi Denney, Jason Boardman, Jane Menken, Tim Wadsworth, Fernando Riosmena, Bob Hummer, Deb Umberson, Rachel Kimbro, and the anonymous reviewers for comments on earlier drafts. 


\begin{abstract}
Important resources from family support systems, employment, and educational attainment inhibit the risk of death. Independently, these factors are particularly salient for suicide, but it is less clear how they combine to affect mortality. Using National Health Interview Survey data from 1986 to $2004(\mathrm{~N}=935,802)$, prospectively linked to mortality through 2006 (including 1,238 suicides), reveals a process of compensation in the way work status and family combine to affect adult suicide: those not working experience more suicide defense from more protective family support systems than do working adults. But a process of reinforcement occurs in the combination of education and family: more education associates with more protection from the family than does less education. The findings demonstrate how families and resources combine to affect mortality in unique ways.
\end{abstract}

Keywords: suicide; family support; family formation; education; employment 
Mortality is a social process (Cockerham 2007, Phelan et al 2004). Substantial bodies of research document the effects of social support and household relationships on health and mortality prospects generally (Berkman \& Glass 2000, Carr \& Springer 2010, Hughes \& Waite 2002, Umberson \& Montez 2010), showing that risks of death and some forms of ill health decrease with increased social ties and more supportive relationships. Research focusing on domestic relationships and suicide are robust, well documented, and wide-ranging. Married persons are less likely than unmarried persons to commit suicide (Kposowa 2000, Kposowa et al 1995), persons in larger families are less likely than persons in smaller families (Denney et al 2009), and persons with children are less likely than persons without children (Denney 2010, Qin et al 2003). Indeed, although families do not always exert positive effects on health (Seeman 2000), individual propensity to suicide is related to how households are configured and living in households with other relatives is generally protective (Denney 2010, Qin et al 2003).

Other social and economic characteristics provide resources that are leveraged to lengthen life. Advantaged groups are positioned to purchase better health, have access to the latest technological advances and knowledge about healthy living, and have incentives to practice healthy habits (Glied \& Lleras-Muney 2008, Pampel et al 2010). Specifically, employment and higher educational attainment extend life by creating additional networks of social support and integration (Berkman \& Glass 2000, House et al 1988, Link \& Phelan 1995). Contemporary research on suicide has shown increased risk for the unemployed (Stack 2000a) and for those who are not active in the work force (Denney et al 2009). Recent empirical work on education and suicide, however, is quite limited and has produced inconsistent findings (Denney et al 2009, Kposowa et al 1995, Stack 2000b). 
Despite conceptually clear links between familial and social and economic factors and suicide, research has focused on their independent effects, ignoring important ways in which they might combine to influence risk. The objective of this study is to illuminate how household formations combine with employment and educational attainment to influence suicide, a leading cause of adult mortality accounting for nearly 36,000 deaths in the United States in 2009 (Kochanek et al 2011).

\section{THE COMBINED INFLUENCE OF HOUSEHOLDS WITH EMPLOYMENT AND EDUCATION: POTENTIAL MECHANISMS}

Households broadly represent an individual's immediate social environment, the daily arena for social support and integration. Households can include spouses, friends, children, other relatives, and even hired caretakers; here, the terms household, family, and living arrangement are used interchangeably. The theoretical work connecting how core elements of household living arrangements, employment, and education — such as social support and integration — influence suicide suggests they may combine in unique ways. Households and employment may combine through a process of compensation - meaning that positive attributes from one factor override negative attributes from the other. Households and education may combine through a process of reinforcement - meaning that positive attributes on both factors work together to further reduce mortality risks.

\section{Independence - Important but Separate}

First, the effects of social support and integration garnered both in the home and through work and education might be distinct enough to create important but separate effects on suicide. To date, this is the approach taken by the majority of researchers concerned with the topic (Denney 2010, Gibbs 2000, Gibbs \& Martin 1964). Households and the relationships built within them 
provide systems of support unmatched in nearly any other area of life (Berkman \& Glass 2000). And employment and education provide economic stability, self-fulfillment, and improved social relations that correspond with reduced risks of taking one's own life (Stack 2000a, Stack 2000b). Many of the explanations for the associations between employment, education, and suicide are similar. Employment increases income and decreases economic hardship. Economic hardship can erode mental and physical health. Indeed, the accumulation of stress from trying to meet the basic needs of a household not only correlates with the odds of getting disease but also with failing to recover from it. In addition, involuntary nonemployment (as opposed to voluntary nonemployment because one is in school or retired) comes with a low sense of social control and low levels of social support (Pearlin et al 1981, Ross \& Mirowsky 1995). Education could also improve health and reduce the odds of suicide by increasing income and enhancing prospects in the labor market. But education does more than enhance economic prospects to improve wellbeing (Cutler \& Lleras-Muney 2008); it increases autonomy and raises social status as well (Mirowsky \& Ross 2003). In all, the literatures on families, employment, and education provide a first hypothesis:

Hypothesis 1: Adults in households which include other persons, who work, and who have more education will have reduced suicide risks compared to adults who live alone, who do not work, and who have less education.

\section{Compensation - Filling a Void}

It is possible that these important factors combine to affect suicide risk. Strong family relationships benefit immune, endocrine, and cardiovascular functions (Umberson \& Montez 2010), and they reduce physiological wear and tear on the body experienced through chronic stress (McEwen 1998, Seeman et al 2002). Persons in compromised socioeconomic states, such 
as the poor and unemployed, often lack such beneficial ties and resources. Adults who do not work more often experience unhealthy levels of stress (Pearlin et al 1981) and engage more often in harmful behaviors, ultimately dying sooner than their employed counterparts from many causes of death (Link \& Phelan 1995, Pampel et al 2010, Phelan et al 2004, Rogers et al 2000) including suicide (Denney et al 2009). The suicide risks of not working could plausibly be reduced via other household members who are employed or contributing to the well-being of household members in other ways.

Indeed, social ties protect against suicide by enhancing a number of beneficial social constructs that researchers have used interchangeably in the past (Berkman \& Glass 2000), including social support, social cohesion, and social capital. Perhaps most importantly for suicide mortality, social relationships increase an individual's level of integration by creating a collective identity through important social bonds to others, what Durkheim ([1897] 1951) referred to as social integration. Social ties, through families and through the workplace, also help individuals adhere to contemporary social norms and expectations, increasing what Gibbs and Martin (1964) refer to as status integration. Integration is a core social element of suicide; more integration corresponds with a reduced risk of death (Wray et al 2011).

Persons who lack good jobs and good pay often suffer not only economically but socially. They lack integration and social cohesion (Phelan et al 2004, Rogers et al 2000). And the more one's identity deviates from established norms, the lower one's well-being (Gibbs 2000, Gibbs \& Martin 1964). For most people, work goes a long way toward creating identity and maintaining a script for navigating everyday life. Not working reduces involvement in collective life, increasing suicide risk while decreasing these important social and economic resources that can be leveraged toward longer lives (Kposowa 2001, Rogers et al 2000). For 
those who do not work, if they have family ties, they may benefit especially from those ties. Thus, those who don't work may compensate for the corresponding social integrative deficits through family support systems. This leads to a hypothesis aimed at the combined effects of living arrangement and employment:

Hypothesis 2. Living in a family household, either with a spouse or with children, is associated with a greater reduction in suicide risk for adults who do not work than for those who do.

\section{Reinforcement - Synergistic Reduction of Risk}

Though employment and education are both positively related to better health and improved overall mortality there are reasons to believe that household formation and health protecting resources from educational attainment (Mirowsky \& Ross 2003) may reinforce each other in their combined impact on suicide. Over the last several decades, more similarly educated persons are increasingly establishing intimate relationships and starting families with other more similarly educated individuals (McPherson et al 2006). For examples, college graduates are increasingly likely to marry other college graduates and persons with low levels of education are increasingly more likely to marry other low educated persons (Schwartz \& Mare 2005).This could result in greater material and social resources that can reduce suicide risks for the highly educated in relationships. That is to say, two positive states together may be better than the sum of the two separately. Coupled with the many positive aspects of educational attainment itself (Cutler \& Lleras-Muney 2008, Mirowsky \& Ross 2003), these more resource rich households may reinforce the benefits of individual educational attainment.

Complicating matters, historical works have documented increased suicide rates with increasing educational attainment (Durkheim [1897] 1951, Masaryk [1881] 1970, Morselli 
1882). Though contemporary research shows that more education is positive in many respects for individuals (Mirowsky \& Ross 2003), these classic works posited that educational attainment reflected increasing individualism and a consequent disconnect from social life. This premise suggests the direct effects of employment and education on suicide may not be the same and runs counter to the prevailing idea that increased mortality risk is linked to disadvantage (i.e. lower education). Studies of the association between education and suicide at the individual-level are quite limited (Stack 2000a), but some recent work suggests that educational attainment is negatively associated with suicide, at least for men (Denney et al 2009).

In the U.S. and other developed nations, persons with more education live longer and healthier lives (Rogers et al 2000). They are also more likely to marry, stay married, have children, and maintain more harmonious and uninterrupted family lives — all independent contributors to better health and reduced suicide risk. But this suggests that relationships between education and suicide are not entirely independent of domestic support systems. Benefits from more education could in some ways rely on, or be enhanced by, household support. If so, both family support and educational attainment together exert special positive effects on suicide. This leads to a hypothesis specific to educational attainment that runs counter to the predicted combined relationship of work status and household formation on suicide risk:

Hypothesis 3. Living in a family household, either with a spouse or with children, is associated with a greater reduction in suicide risk for adults with more education than for those with less education.

\section{Gender and Age Considerations in the Study of Suicide}

Importantly, the rates of and contributors to suicide are very different by gender. Men die from suicide in the United States at a rate four times that of women (Kochanek et al 2011). Research 
on health and mortality has found that family living, and particularly the benefits associated with marriage, may be more important for men than women (Umberson 1992, Waite \& Gallagher 2000). This pattern holds for suicide (Stack 2000a, Stack 2000b) as men's, but not women's, risk is closely tied to marital status (Denney et al 2009).

At the same time, men's notions of status center largely on areas outside the home (Shiner et al 2009), for example on educational status and employment outlook. Even in the most developed nations with large proportions of women in the work force, female identity may slant more toward the family than toward work life (Girard 1993). Recent analyses using individuallevel data have shown that men and women who do not work have higher suicide risks than their employed counterparts (Denney et al 2009). However, the same study showed that higher educational attainment lowered risk among men but education was unrelated to women's risk. Research has suggested the larger number of suicides among men than among women is a result of the importance placed by men on economic success, a primary male role (Stack 2000a). Thus, men who do not work may rely more heavily on sources of support in the household. And men who pursue individual achievement through higher education may mitigate any social support and integration deficits through the household. Meanwhile, families, work status, and education may independently influence women's risk. No work to date has examined the combined influence of family formation with work status and education on suicide mortality risk by gender. If family life and status outside the home are generally more important for men's than for women's mortality prospects and support is found for the processes of compensation and reinforcement then two gender-specific hypotheses follow:

Hypothesis 4. Living in a family household, either with a spouse or with children, will reduce the risk of suicide further for men who are not working than for men who are working. 
The association of household living arrangement with suicide risk will not vary by women's work status.

Hypothesis 5. Living in a family household, either with a spouse or with children, will reduce the risk of suicide further for men with more education than for men with less education. The association of household living arrangement with suicide risk will not vary by women's educational attainment.

Finally, aggregate analyses of suicide rates show that age patterns of suicide are related to period and cohort effects, as individuals find themselves competing for good jobs, compatible mates, and general stability over the life course (Pampel 1996, Phillips et al 2010). In the United States, suicide generally increases with age peaking for men at the oldest ages and doing so in middle age for women, followed by a slight decline at the oldest ages for women (Stack 2000b). Studies explaining age differences in suicide at the individual level are limited (Stack 2000b) but existing literatures identifying varying mortality risks by age (Berkman et al 1992, Seeman 2000) and life course theory suggest that occupying a non-normative status can have more harmful consequences at specific ages (Gibbs 2000). Thus, processes of compensation and reinforcement might vary importantly by age but sample limitations prevent tests of these arguments here. Nonetheless, as described below, all analyses account for age and other important covariates.

\section{METHODS}

\section{Data}

The data come from combining multiple years of the National Health Interview Survey (NHIS), linked to prospective mortality through the Linked Mortality Files (LMF). The Integrated Health Interview Series (IHIS), an initiative through the Minnesota Population Center at the University of Minnesota, streamlines an otherwise arduous data construction process and provides the 
complete data set used here (Minnesota Population Center 2010). NHIS years include 1986 through 2004, and LMF cover 1986 through 2006. Designed as a cross-sectional household survey, the NHIS annually collects information from approximately 30,000 to 40,000 households, obtaining response rates consistently at or above $90 \%$ (NCHS various years).

The National Center for Health Statistics (NCHS) recently completed its fourth mortality follow-up with NHIS respondents (NCHS 2009). To create the LMF, NCHS uses a probabilistic mortality matching scheme that assigns weights to multiple factors including social security number, first and last name, and date of birth. Importantly, because of confidentiality concerns public-use mortality data include deaths only for those over age 17. Accordingly, respondents under age 18 , comprising $28 \%$ of the original sample and $6 \%$ of all suicides in 2009 (Kochanek et al 2011), are included in the construction of household variables (described below) and are subsequently dropped.

An additional 3\% of cases are dropped because they are missing data on the key variables used in the empirical analyses or because NCHS designates them as ineligible to be linked to prospective mortality; ineligibles are cases whose records include insufficient identifying data, such as name and social security number, to create a mortality record (NCHS 2009). For the years used here, fewer than $3 \%$ of cases are deemed ineligible in any single year, and NCHS (2009) provides weights that adjust for the exclusion of ineligible records. Finally, because of mortality selection at the oldest ages and because most adults complete their education and enter the workforce by early adulthood, the final data set includes information on 935,802 adults aged 25 to 65 residing within 564,594 households. The individual records are linked to 1,238 suicide deaths through 2006.

\section{Measures}


The dependent variable, suicide mortality, is coded 1 for suicidal death, defined in the World Health Organization's (2007) $10^{\text {th }}$ revision of the International Statistical Classification of Diseases, Injuries, and Causes of Death (ICD-10) as death from intentional self-harm (codes $\mathrm{X} 60-\mathrm{X} 84)$; it is coded 0 for all other respondents, who either survived the follow-up or died from other causes.

The NHIS collects a core set of sociodemographic, socioeconomic, and health measures (NCHS various years). However, the amount of detail sometimes varies from year to year; to maintain consistency across all years, this study uses some more broadly defined variables. Age is a continuous variable and gender is coded dichotomously with women as the referent, and multivariate analyses stratify models separately for men and women. Race is also a dichotomous variable, with non-Hispanic white as the referent.

Separate dummy variables capture educational attainment and work status, with referents of greater than high school and employed, respectively. Only some years of the NHIS contain more detailed measures of education (NCHS various years), so the less detailed measure is used to allow investigation over the entire study period. Though not ideal, the education dummy variable captures important differences in status. Work status separates employed individuals from those who reported that they were unemployed or not in the labor force. Compared to work and education, income has less influence on suicide mortality (Denney et al 2009, Kposowa et al 1995, Stack 2000a). Thus, income is included primarily as a control measure. A continuous measure of income is approximated by taking the midpoint of the categories defined by NCHS and by estimating a median value for the open ended category (Parker \& Fenwick 1983). The value is then adjusted to account for varying purchasing power among families of differing sizes (see Van der Gaag \& Smolensky 1982), and the consumer price index is used to regulate changes 
in purchasing power over time. Missing data for income is estimated using a number of covariates and stochastic variation is incorporated into the predicted values of income to better represent variability in the actual income data (see Gelman and Hill 2007). A logged transformation of the continuous measure is included in the multivariate models to account for its skewed distribution; models were estimated with and without the missing income data and no discernible differences appeared.

The NHIS person files include no measures on mental health, but research suggests that subjective reports of health encapsulate many dimensions of overall health and they vary importantly across gender and socioeconomic status (Idler et al 1999, Schnittker 2005). Thus, self-rated health is included in models as a broad indicator of current health; it is measured continuously from 0 , poor health, to 4 , excellent health. Controlling for health status also helps with issues of selection; poor health at baseline may have an influence on family type and economic resources, increasing suicide risk.

To take advantage of the household nature of the NHIS data, multiple variablesincluding marital status and household size — are used to identify household types. Each household in the NHIS is assigned a unique numeric identifier, as is each person; in combination, these numbers enable the analyst to ascertain who lives in which household. Then, a series of steps identifies the configuration of the household. First, a variable identifies households that included children under age 18 . Second, a variable indicates whether a marriage existed within the household. A third variable records whether households include other nonchild relatives, and a fourth, whether unrelated persons reside in the dwelling. Because suicide is a relatively rare cause of death, the types of households included in the analyses are limited to those that capture critical aspects of domestic integration. Married-couple families without children, married- 
couple families with children under the age of 18 , unmarried families with children under the age of 18, and unmarried families without children are included. Unmarried families include adults who are not currently married but may have been divorced or widowed, as well as those never married. Family types with and without children can include other nonchild relatives and unrelated adults. Separate analyses of the more intricate family types do not alter interpretations. For example, separating married-couple-only households from married-couple households with other relatives or unrelated persons produces much the same results. Some household configurations are more common than others, but all household configurations used in the analysis represent the living situation of at least $4.0 \%$ of the sample. The reference category in all multivariate analyses is an adult living alone.

\section{Estimation}

Multivariate analyses investigating the relationships among individual characteristics, household living arrangements, and suicide employ a Cox Proportional Hazard framework (Allison 1984). The Cox models are particularly useful because they do not impose a distribution of death across age, nor do they require the analyst to choose a particular form for the times of survival specified (Allison 1984). The model declares the hazard rate for the $j$ th respondent as $\mathrm{h}\left(\mathrm{t} \mid \mathrm{x}_{\mathrm{j}}\right)=\mathrm{h}_{0}(\mathrm{t}) \exp \left(\mathrm{x}_{\mathrm{j}} \beta_{\mathrm{x}}\right)$ where the coefficients $\beta_{\mathrm{x}}$ are estimated from the data using a partial likelihood approach (Hoffman 2004).

A key assumption of the Cox model is proportional hazards. Tests of the proportionality assumption following a generalization formulated by Grambsch and Therneau (1994) reveal that the assumption is violated for the full model, but not for models stratified by gender. These results, together with evidence suggesting that Cox estimates are sturdy despite proportionality 
assumptions when based on large nationally representative samples (Therneau \& Grambsch 2000), provide some confidence in the techniques used here.

Further robustness checks included examining only those suicides that occurred within 5 years of interview, and testing for differences between an early period (1986 to 1994) and a late period (1996 to 2004). The results from these models are available upon request and are much the same as those presented here. All results from the Cox Proportional Hazard analyses are reported as hazard ratios (HRs). Stata 12 (StataCorp 2010) incorporates sample weights and estimates robust standard errors that account for the NHIS stratified and clustered sampling design (NCHS various years).

Finally, the hypotheses require stratifying models by work status and educational level, and by gender. To evaluate effects across groups, interaction models are estimated and Wald tests are calculated using the results from those models, a procedure referred to as the generalized linear model solution to compare model results (Hoffman 2004). The Wald test is distributed $\chi^{2}$ and provides the analyst with some important flexibility, including the ability to evaluate differences across all household types and differences across specific types of household configuration. Degrees of freedom are equal to the total number of household types for the former (four) and equal to one for the latter.

The multivariate analyses proceed by first establishing the relationship between household living arrangement and suicide for the full sample and separately by gender (Table 2). Then, models are estimated to assess the effects of household living arrangement by work status and educational attainment on suicide risk (Table 3). The Wald test information from these models represent tests of two-way interactions (i.e. living arrangement $\mathrm{x}$ work status). Finally, models with three-way interactions (i.e. living arrangement $\mathrm{x}$ education $\mathrm{x}$ gender) are estimated 
to further delineate household living arrangement by work status and educational achievement for men and women. The three-way interaction models also include all one-way (i.e. education) and two-way terms (i.e. living arrangement $\mathrm{x}$ education). Table 4 then presents the Wald test information for significant three-way interaction models. The Wald test information provided in Tables 3 and 4 are used to assess the proposed processes of combined influence. If a process of compensation occurs, supportive household formations will reduce suicide risk more for those with fewer resources (i.e. not working). If reinforcement occurs, the opposite will be observedthose with more resources will benefit more from supportive household types (i.e. more highly educated). Finally, if living arrangements, work status, and educational attainment exert independent effects on mortality risk, no significant differences across groups will be observed in the Wald tests.

\section{RESULTS}

Table 1 provides weighted means of the individual and household-level covariates for the full sample and for those who committed suicide over the follow-up period. The average age for those who committed suicide is similar to the average age of the sample. There are large disparities between the full sample and those who committed suicide by gender and race. Notably, as in national trends (Kochanek et al 2011), the overwhelming majority of those in the sample who committed suicide were white, making detailed analyses by racial group difficult. Other individual-level differences between the full sample and those who committed suicide are more modest but are also consistent with current knowledge (Denney et al 2009, Stack 2000a, Stack 2000b).

(Table 1 about here) 
Table 1 reveals important differences in living arrangements between the full sample and those who committed suicide. While $12 \%$ of the sample is composed of single persons living alone, $22 \%$ of individuals who died from suicide lived alone. Along the same lines but less strikingly, $26 \%$ of the sample lived in married households without children, and those persons accounted for $28 \%$ of all suicides. In contrast, $48 \%$ of the full sample lived in households that included a marriage and children, and those persons accounted for only $39 \%$ of suicides. Finally, multiperson households without a marriage, both with and without children, accounted for smaller proportions of both the full sample and the suicide deaths.

Table 2 provides hazard ratios (HR) of the individual and household covariates first for the full sample and then separately for men and women. For the full sample, compared to a single adult living alone, living in households that included other members was associated with suicide risks less than 1.0. The key individual-level variables, work status and education, show that not working associated with a $65 \%$ higher risk of suicide over the follow-up period but having less education, compared to having more, did not significantly associate with suicide risk. Other individual-level controls in the full model show that men were at over four times the risk of suicide compared to women; nonwhites experienced $60 \%$ the risk of whites; income had no effect; and more positive health ratings associated with lower suicide risks.

\section{(Table 2 about here)}

Models by gender in Table 2 generally show that the risk of suicide was lower for those living in households with other adults and children, compared to living alone. Men in unmarried households without children had lower risk of suicide than men who lived alone but the same comparison among women shows that unmarried women who live with others face similar risks of suicide compared to women who live alone. The difference between men and women in that 
household type is marginally significant $(\mathrm{p}=.08$; results available upon request). Men and women who were not working were likelier to commit suicide over the follow-up compared to their working counterparts. But while less educated men showed a higher risk of suicide than more educated men, the education association is reversed among women (and significantly different from men, $\mathrm{p} \leq .05$; available upon request). The other control variables have similar and expected relationships for both men and women. In all, Table 2 suggests that family living, work status, and education have important relationships with suicide mortality.

Table 3 presents results from Cox analysis testing the combined associations of household formation with work status (Panel A) and education (Panel B). Panel A provides some support for the compensation perspective; it shows that those who were not working experienced more risk reduction from living in family households over the follow-up than did those who were working $\left(\chi^{2}=7.8, \mathrm{p} \leq .10\right)$. This was most evident in households that included children. For adults not working, compared to living alone, those living in married-couple-with-children households had $65 \%$ lower and those living with children but without marriage had $49 \%$ lower suicide risks. By comparison for working adults, those in married-couple households with children had 52\% lower suicide risks and risk for working individuals in unmarried households with children was statistically indistinguishable from adults living alone.

(Table 3 about here)

With regard to education, Panel B of Table 3 shows that education and family combine synergistically to influence risk. In accord with the reinforcement perspective, Panel B shows that more educated persons had lower suicide risks in family households than did less educated persons $\left(\chi^{2}=11.6, \mathrm{p} \leq .05\right)$. These lower risks were concentrated in households that included a marriage. More educated persons experienced significantly lower suicide risk in married-couple 
households with $(\mathrm{HR}=0.35)$ and without children $(\mathrm{HR}=0.49)$ than did less educated persons $(\mathrm{HRs}=0.58$ and 0.84 respectively).

Finally, models were estimated with three-way interactions for living arrangement by gender by work status and for living arrangement by gender by education (also including all other control measures and the corresponding two-way and one-way terms; available by request). No significant interaction for living arrangement $\mathrm{x}$ gender $\mathrm{x}$ work status was found, suggesting the process of compensation witnessed in the full sample does not vary by gender. A three-way interaction for living arrangement $\mathrm{x}$ gender $\mathrm{x}$ education provides limited evidence that the reinforcement of family and education may vary by gender $(\mathrm{p} \leq .10)$. Accordingly, Table 4 provides Wald tests for the interaction between living arrangement and education separately for men and women. The process of reinforcement identified in Table 3 can most clearly be seen among men $\left(\chi^{2}=10.5, p \leq .05\right)$. Specifically, the risk of suicide for men living in married-couple households with and without children varies by education in ways that are consistent with the reinforcement perspective. Panel B shows that, overall, women's risks of suicide did not significantly differ by education $\left(\chi^{2}=6.6, p=.16\right)$. However, similar to men, risk for suicide for women in married couple families with children does vary by educational attainment.

(Table 4 about here)

\section{DISCUSSION}

As a leader of premature mortality in the United States over the last 50 years, suicide has aroused continued concern from policy makers, researchers, and public health officials alike. Indeed, the seemingly individual act of suicide possesses a social character. Sources of social support and integration, including those found in the home, at work, and through educational attainment have documented relationships with health. Results on twenty years of U.S. data linked to prospective 
mortality suggest that household support systems and individual employment and education are important contributors of suicide risk and that they also combine in unique ways to influence suicide.

For those not working, a process of compensation was revealed suggesting these adults may rely more heavily on households that include other adults and children to lower risks of suicide. The combination of education and household formation, however, revealed a process of reinforcement: suggesting more educated adults may experience more protection from the household than do less educated adults.

Support through household relationships and responsibilities may be an essential consideration of suicide risk for adults who are out of the labor force-it could serve as a last line of protection against the potential loss of meaning and social ties through work. This protection may be particularly salient for those in households that include children. Marriage and family life, especially the rearing of children, may replace the structure and meaning that persons typically rely on employment to provide. Family life may also encourage the avoidance of risky behavior associated with criminal activity and substance abuse (especially men) that place persons at increased risk for a number of poor health and mortality outcomes. This process of compensation follows the logic and findings of the relationships between disadvantage and health. Social support and greater resources are better for long-term health and mortality prospects. It is reasonable to deduce that a deficiency in one area may lead persons to depend more heavily on another. Doing so explicitly recognizes the importance of considering both employment status and family type in tandem rather than separately.

Perhaps more elusive, from a disadvantage perspective, is an explanation of why more educated persons might experience more protection via support from the home than less 
educated persons. Whereas the interaction between work status and household living arrangement appeared strongest in households that included children, the interactive relationship between living arrangement and education was exemplified in households where a marriage was present. Both classical sociological theory and contemporary research on the benefits of educational attainment provide places to begin to understand this finding. Durkheim ([1897] 1951) contended that education may be accompanied by a general loss of social connectedness, making domestic relationships all the more essential for more educated individuals. More contemporary works suggest that education is itself a powerful resource but also that the benefits of marriage are greater, for example, for more highly educated persons because over time, educational heterogeneity has declined such that more highly educated persons tend to marry and stay married to other highly educated persons (McPherson et al 2006, Schwartz \& Mare 2005). This might result in greater material and social resources that are leveraged toward better health and improved longevity for the highly educated in relationships. In turn, those who are less educated benefit less from marriage because they typically are married to someone who also has low levels of education. The combined association of household composition and education may be more clearly related to men's risk but the association between living in a married couple household with children and suicide varied by educational attainment for both men and women. Therefore, more educated men and women may synergistically experience the benefits that come with educational attainment and more resourceful marital relationships to reduce the risk of suicidal death.

Additional insights might be gained from age-specific models. Indeed, suicide research has identified middle age adults as a group with stability and comfort in personal and professional life (Stack 2000b), leading to high social integration, good jobs, and positions of 
power. While education, for example, can protect health, it may exert special positive effects for adults who have maintained domestic and achieved economic stability in middle age. Variations in combined associations across the life course represent a fruitful area of future research with larger samples of adults living in various household types.

The NHIS-LMF is large and nationally representative, but not without other limitations. The public-use release of mortality data limits the amount of information on the deceased; more detail at time of death would allow examination of changing status from interview to death. This may be relevant for the differences in the ways employment and education combine with living arrangement to influence mortality risk. Educational attainment is relatively stable over time but employment status at time of interview is more likely to change by time of death, especially if the respondent encounters a medical issue that requires the stoppage of work or if the length of time between interview and death is long. Though the results presented partially address these concerns by accounting for health status at time of interview and exploring shortened follow-up periods, these limitations should be considered when interpreting the results.

Further, the cross-sectionality of the NHIS limits investigation of issues of selection. For example, measures of health before and after a change in work status might better capture relationships, as those not working are also likely in poorer mental health (Platt 1984). In addition, health status and other factors select adults into and out of certain living arrangements. Finally, core NHIS data do not include measures for other established predictors of mortality. Some of the more important considerations in the study of suicide specifically include religiosity (Ellison et al 1997), genetic propensities (Brent \& Mann 2005), and cultural norms relating to suicide acceptability (Cutright \& Fernquist 2000). 
Research on social contributors to health has shifted productively away from historical doctrines that first centered solely on structural, and later on individual, forces (Cockerham 2007). The findings here support an approach that explores explanations which lie somewhere in the middle ground, acknowledging that family and individual characteristics can combine to affect mortality in unique ways. 


\section{REFERENCES}

Allison PD. 1984. Event History Analysis: Regression for Longitudinal Event Data. Beverly Hills, CA: Sage Publications.

Berkman LF, Glass T. 2000. Social Integration, Social Networks, Social Support, and Health In Social Epidemiology, ed. LF Berkman, I Kawachi, pp. 137-73. Oxford: Oxford University Press

Berkman LF, Leo-Summers L, Horwitz RI. 1992. Emotional Support and Survival after Myocardial Infarction: A Prospective, Population-based Study of the Elderly. Annals of Internal Medicine 117: 1003-09

Brent DA, Mann JJ. 2005. Family Genetic Studies, Suicide, and Suicidal Behavior. American Journal of Medical Genetics Part C: Seminars in Medical Genetics 133C: 13-24

Carr D, Springer KW. 2010. Advances in Families and Health Research in the 21st Century. Journal of Marriage and Family 72: 743-61

Cockerham WC. 2007. Social Causes of Health and Disease. Cambridge, UK: Polity Press.

Cutler DM, Lleras-Muney A. 2008. Education and Health: Evaluating Theories and Evidence In Making Americans Healthier: Social and Economic Policy as Health Policy, ed. R Schoeni, JS House, GA Kaplan, H Pollack, pp. 29-60. New York: Russell Sage Foundation

Cutright P, Fernquist RM. 2000. Effects of Social Integration, Period, Region, and Culture of Suicide on Male Age-specific Suicide Rates: 20 Developed Countries, 1955-1989. Social Science Research 29: 148-72

Denney JT. 2010. Family and Household Formations and Suicide in the United States. Journal of Marriage and Family 72: 202-13

Denney JT, Rogers RG, Krueger PM, Wadsworth T. 2009. Adult Suicide Mortality in the United States: Marital Status, Family Size, Socioeconomic Status, and Differences by Sex. Social Science Quarterly 90: 1167-85

Durkheim E. [1897] 1951. Suicide: A Study in Sociology. New York: The Free Press.

Ellison CG, Burr JA, McCall PL. 1997. Religious Homogeneity and Metropolitan Suicide Rates. Social Forces 76: 273-99

Gibbs JP. 2000. Status Integration and Suicide: Occupational, Marital, or Both? Social Forces 78: $949-68$

Gibbs JP, Martin WT. 1964. Status Integration and Suicide. Eugene: University of Oregon Press.

Girard C. 1993. Age, Gender, and Suicide: A Cross-National Analysis. American Sociological Review 58: 553-74

Glied S, Lleras-Muney A. 2008. Technological Innovation and Inequality in Health. Demography 45: 741-61

Grambsch PM, Therneau TM. 1994. Proportional Hazards Tests and Diagnostics Based on Weighted Residuals. Biometrika 81: 515-26

Hoffman JP. 2004. Generalized Linear Models: An Applied Approach. Boston: Pearson Education, Inc.

House JS, Landis KR, Umberson D. 1988. Social Relationships and Health. Science 241: 540-45 Hughes ME, Waite LJ. 2002. Health in Household Context: Living Arrangements and Health in Late Middle Age. Journal of Health and Social Behavior 43: 1-21

Idler EL, Hudson SV, Leventhal H. 1999. The Meanings of Self-Rated Health: A Qualitative and Quantitative Approach. Research on Aging 21: 458-76 
Kochanek KD, Xu J, Murphy SL, Miniño AM, Kung H-C. 2011. Deaths: Final Data for 2009. National Vital Statistics Reports 60

Kposowa AJ. 2000. Marital Status and Suicide in the National Longitudinal Mortality Study. Journal of Epidemiology and Community Health 54: 254-61

Kposowa AJ. 2001. Unemployment and Suicide: a Cohort Analysis of Social Factors Predicting Suicide in the U.S. National Longitudinal Mortality Study. Psychological Medicine 31: 127-38

Kposowa AJ, Breault KD, Singh GK. 1995. White Male Suicide in the United States: A Multivariate Individual-Level Analysis. Social Forces 74: 315-25

Link BG, Phelan J. 1995. Social Conditions as Fundamental Causes of Disease. Journal of Health and Social Behavior Extra Issue: 80-94

Masaryk TG. [1881] 1970. Suicide and the Meaning of Civilization. Chicago, IL: University of Chicago Press.

McEwen BS. 1998. Protective and Damaging Effects of Stress Mediators. The New England Journal of Medicine 338: 171-79

McPherson M, Smith-Lovin L, Brashears ME. 2006. Social isolation in America: Changes in core discussion networks over two decades. American Sociological Review 71: 353-75

Minnesota Population Center. 2010. Integrated Health Interview Series: Version 3.0. Minneapolis: University of Minnesota

Mirowsky J, Ross CE. 2003. Education, Social Status, and Health. Hawthorne, NY: Aldine De Gruyter.

Morselli H. 1882. Suicide: An Essay on Comparative Moral Statistics. New York: D. Appleton and Company.

National Center for Health Statistics. 2009. The National Health Interview Survey (1986-2004) Linked Mortality Files, mortality follow-up through 2006. Office of Analysis and Epidemiology. Hyattsville, MD

-----. various years. 1986-2004 National Health Interview Surveys: Core Data. US Department of Health and Human Services. Hyattsville, MD

Pampel FC. 1996. Cohort Size and Age-Specific Suicide Rates: A Contingent Relationship. Demography 33: 341-55

Pampel FC, Krueger PM, Denney JT. 2010. Socioeconomic Disparities in Health Behaviors. Annual Review of Sociology 36: 349-70

Parker RN, Fenwick R. 1983. The Pareto Curve and Its Utility for Open-Ended Income Distributions in Survey Research. Social Forces 61: 873-85

Pearlin LI, Lieberman MA, Menaghan EG, Mullan JT. 1981. The Stress Process. Journal of Health and Social Behavior 22

Phelan JC, Link BG, Diez-Roux A, Kawachi I, Levin B. 2004. "Fundamental Causes" of Social Inequalities in Mortality: A Test of the Theory. Journal of Health and Social Behavior 45: 265-85

Phillips JA, Robin AV, Nugent CN, Idler EL. 2010. Understanding Recent Changes in Suicide Rates Among the Middle-aged: Period or Cohort Effects? Public Health Reports 125: 680-88

Platt S. 1984. Unemployment and Suicidal Behavior: a Review. Social Science \& Medicine 19: 93-115 
Qin P, Agerbo E, Mortensen PB. 2003. Suicide Risk in Relation to Socioeconomic, Demographic, Psychiatric, and Familial Factors: A National Register-Based Study of All Suicides in Denmark, 1981-1997. American Journal of Psychiatry 160: 765-72

Rogers RG, Hummer RA, Nam CB. 2000. Living and Dying in the USA: Behavioral, Health, and Social Differentials of Adult Mortality. New York: Academic Press.

Ross CE, Mirowsky J. 1995. Does employment affect health? Journal of Health and Social Behavior: 230-43

Schnittker J. 2005. Cognitive Abilities and Self-Rated Health: Is There a Relationship? Is it Growing? Does it Explain Disparities? Social Science Research 34: 821-42

Schwartz CR, Mare RD. 2005. Trends in educational assortative marriage from 1940 to 2003. Demography 42: 621-46

Seeman TE. 2000. Health Promoting Effects of Friends and Family on Health Outcomes in Older Adults. American Journal of Health Promotion 14: 362-70

Seeman TE, Singer BH, Ryff CD, Love GD, Levy-Storms L. 2002. Social Relationships, Gender, and Allostatic Load across Two Age Cohorts. Psychosomatic Medicine 64: 395406

Shiner M, Scourfield J, Fincham B, Langer S. 2009. When things fall apart: Gender and suicide across the life-course. Social Science \& Medicine 69: 738-46

Stack S. 2000a. Suicide: A 15-Year Review of the Sociological Literature Part I: Cultural and Economic Factors. Suicide and Life-Threatening Behavior 30: 145-62

Stack S. 2000b. Suicide: A 15-Year Review of the Sociological Literature Part II: Modernization and Social Integration Perspectives. Suicide and Life-Threatening Behavior 30: 163-76

StataCorp. 2010. Stata Statistical Software: Release 12. College Station, TX: Stata Corporation

Therneau TM, Grambsch PM. 2000. Modeling Survival Data: Extending the Cox Model. New York, NY: Springer.

Umberson D. 1992. Gender, Marital Status, and the Social Control of Health Behavior. Social Science \& Medicine 34: 907-17

Umberson D, Montez JK. 2010. Social Relationships and Health: A Flashpoint for Health Policy. Journal of Health and Social Behavior 51: S54-S66

Van der Gaag J, Smolensky E. 1982. True Household Equivalence Scales and Characteristics of the Poor in the United States. Review of Income and Wealth 28: 17-28

Waite LJ, Gallagher M. 2000. The Case for Marriage: Why Married People are Happier, Healthier, and Better Off Financially. New York: Doubleday.

World Health Organization. 2007. International Statistical Classification of Diseases and Related Health Problems, 10th Revision. Available at http://www.who.int/classifications/apps/icd/icd10online

Wray M, Colen C, Pescosolido B. 2011. The Sociology of Suicide. Annual Review of Sociology 37: $505-28$ 
Table 1. Weighted Means of Individual Characteristics and Living Arrangements, For the Full Sample and For Those Who Died of Suicide Over the Follow-up Period, U.S. Adults aged 25 to 65, 1986-2006.

Full Sample $(\mathrm{N}=935,802) \quad$ Suicide Deaths $(\mathrm{N}=1,238)$

Individual Characteristics

Age

Gender (men=1)

Race (non-Hispanic white=1)

Education

high school or less

more than high school

Work Status

unemployed or not in the labor force

working

Household Income

less than or equal to $\$ 20,000$

Self-rated health

\section{Family / Household Living Arrangement}

single living alone

married couple without children

married couple with children

unmarried with children

unmarried without children
42.4

0.49

0.75

0.50

0.50

0.24

0.76

0.21

2.87

0.12

0.26

0.48

0.10

0.04
41.9

0.78

0.88

0.56

0.44

0.29

0.71

0.30

2.59

0.22

0.28

0.39

0.09

0.02

Source: NHIS-LMF 1986-2006 
Table 2. Cox Proportional Hazard Ratios for the Risk of Suicide Mortality, U.S. Adults Age 25 to 65 .

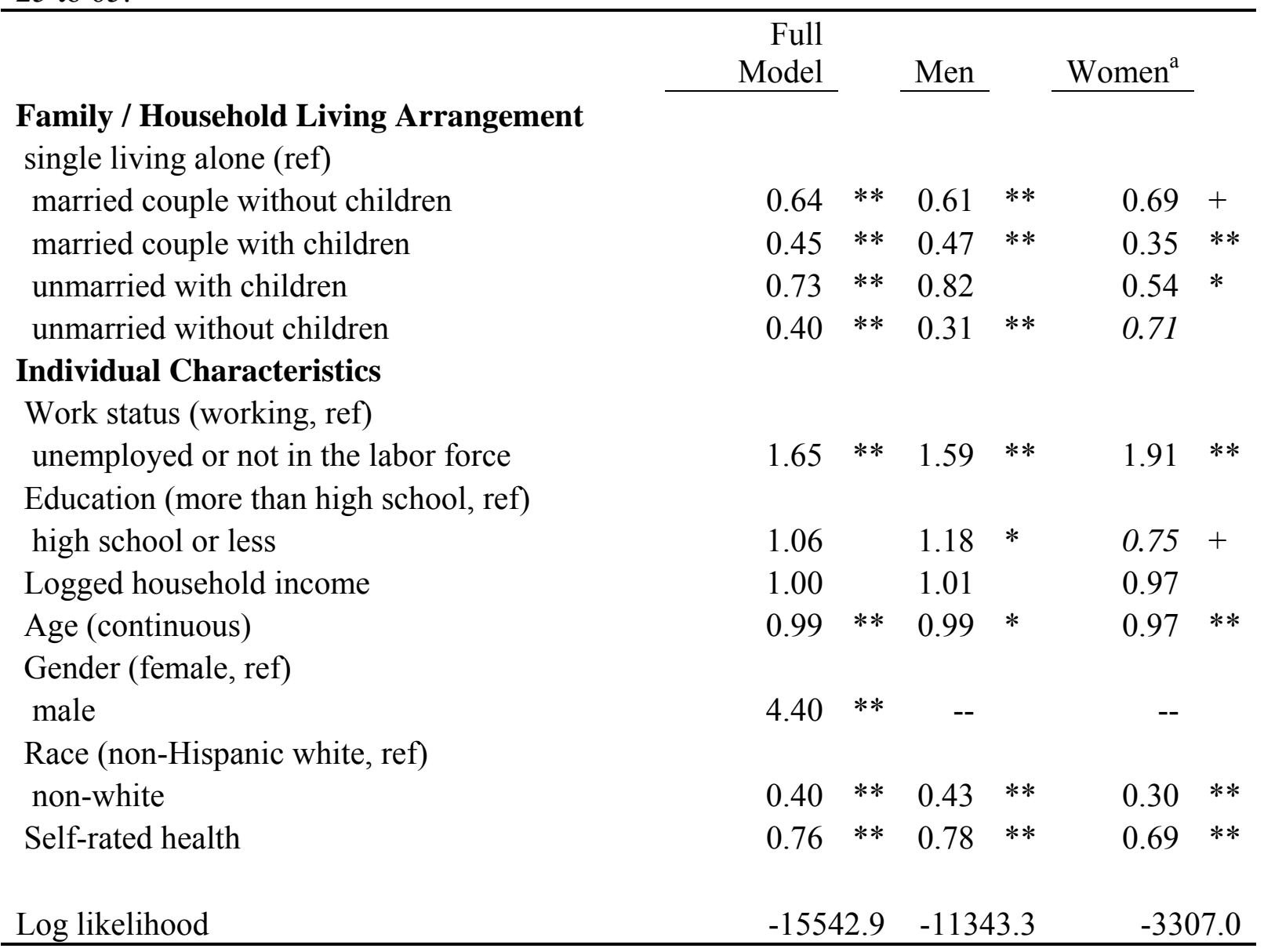

Source: NHIS-LMF 1986-2006

${ }^{+} \mathrm{p} \leq .10 ; * \mathrm{p} \leq .05 ; * * \mathrm{p} \leq .01$

${ }^{a}$ Italic indicates significant difference $(\mathrm{p} \leq .10)$ from men. 
Table 3. Cox Proportional Hazard Ratios and Wald Tests of Interactions for the Risk of Suicide Mortality, By Work Status and Education., ${ }^{\text {a,b }}$

\section{Panel A. Work Status}

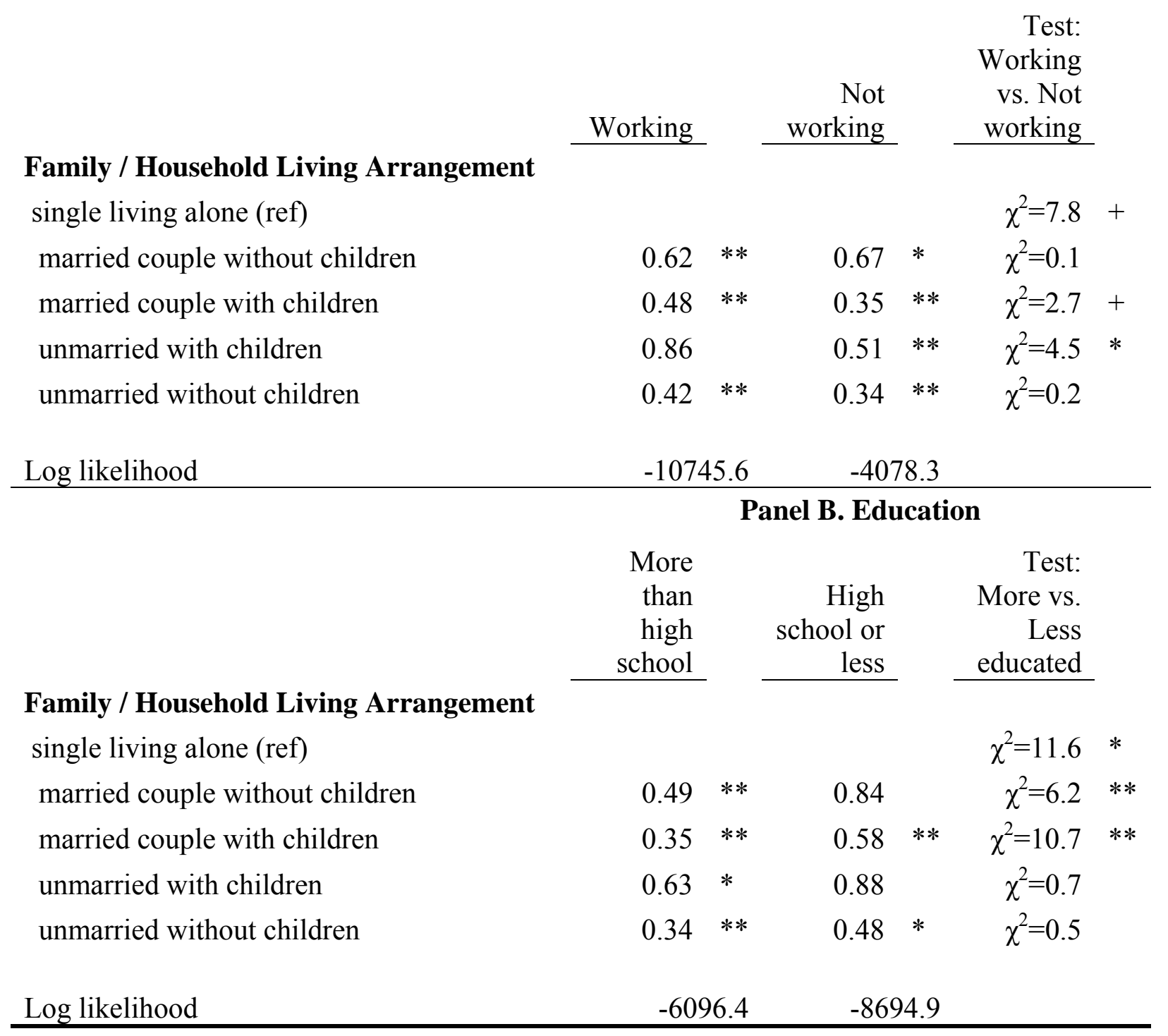

Source: NHIS-LMF 1986-2006

${ }^{+} \mathrm{p} \leq .10 ;{ }^{*} \mathrm{p} \leq .05 ; * * \mathrm{p} \leq .01$

${ }^{a}$ All models include adults age 25 and older and control for all individual level sociodemographic, socioeconomic, and self-rated health covariates.

${ }^{\mathrm{b}}$ Tests across work status and education come from models that pool individuals from the demographic subgroup presented. These tests are provided for the living arrangements as a whole with $\mathrm{df}=4$ and for the individual living arrangements with $\mathrm{df}=1$. 
Table 4. Cox Proportional Hazard Ratios and Wald Tests of Interactions for the Risk of Suicide Mortality by Education and Gender. ${ }^{a, b}$

\section{Panel A. Men}

\begin{tabular}{rrr} 
& Panel A. Men & Test: \\
More than & High & More vs. \\
high & school or & Less \\
school & less & educated \\
\cline { 2 - 2 }
\end{tabular}

\section{Family / Household Living Arrangement}

single living alone (ref)

married couple without children

married couple with children

unmarried with children

unmarried without children

$\begin{array}{rlllll} & & & & \chi^{2}=10.5 & * \\ 0.46 & * * & 0.80 & & \chi^{2}=6.4 & * * \\ 0.38 & * * & 0.58 & * * & \chi^{2}=7.5 & * * \\ 0.76 & & 0.94 & & \chi^{2}=0.3 & \\ 0.36 & * * & 0.28 & * * & \chi^{2}=0.2 & \end{array}$

Log likelihood

$-5073.9$ $-8690.5$

Panel B. Women

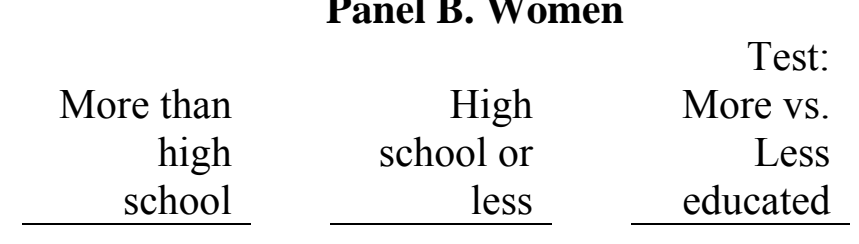

Family / Household Living Arrangement

single living alone (ref)

married couple without children

$\begin{array}{llllll} & & & & & \chi^{2}=6.6 \\ 0.60+ & 0.87 & & \chi^{2}=0.8 \\ 0.28 * * & 0.44 & * * & & \\ \chi^{2}=3.9 & * \\ 0.46 * & 0.64 & & \chi^{2}=1.2 \\ 0.99 & & 1.47 & & \chi^{2}=3.8\end{array}$

Log likelihood

$-1594.2$

$-2138.9$

Source: NHIS-LMF 1986-2006

${ }^{+} \mathrm{p} \leq .10 ; * \mathrm{p} \leq .05 ; * * \mathrm{p} \leq .01$

${ }^{a}$ All models control for all individual level sociodemographic, socioeconomic, and selfrated health covariates.

${ }^{\mathrm{b}}$ Tests across education were estimated after finding a significant three-way interaction ( $\mathrm{p}$ $\leq .10$ ) between living arrangement, gender, and education in a model that included all oneway terms as well as two-way terms and the three-way term. The tests presented come from models that pool individuals from the demographic subgroup presented. These tests are provided for the living arrangements as a whole with $\mathrm{df}=4$ and for the individual living arrangements with $\mathrm{df}=1$. 
